\title{
Cluster of botulism among Dutch tourists in Turkey, June 2008
}

C M Swaan (Corien.Swaan@rivm.nl) ${ }^{1}$, I M van Ouwerkerk ${ }^{1}$, H J Roest ${ }^{2}$

1. Centre for Infectious Disease Control, National Institute for Public Health and the Environment (RIVM), the Netherlands

2. Central Veterinary Institute of Wageningen UR (CVI), Lelystad, the Netherlands

Citation style for this article: Swaan CM, van Ouwerkerk IM, Roest HJ. Cluster of botulism among Dutch tourists in Turkey, June 2008. Euro Surveill. 2010;15(14): pii=19532. Available online: http://www.eurosurveillance.org/ViewArticle.aspx?Articleld=19532

This article has been published on 8 April 2010

In June 2008, three Dutch tourists participating in a mini-cruise in Turkey needed urgent repatriation for antitoxin treatment because of symptoms of botulism. Because there was a shortage of antitoxin in the Netherlands, an emergency delivery was requested from the manufacturer in Germany. An outbreak investigation was initiated into all nine cruise members, eight of whom developed symptoms. C. botulinum type B was isolated in stool culture from four of them. No other patients were notified locally. Food histories revealed locally purchased unprocessed black olives, consumed on board of the ship, as most likely source, but no leftovers were available for investigation. $C$. botulinum type $\mathrm{D}$ was detected in locally purchased canned peas, and whilst type $D$ is not known to be a cause of human intoxication, its presence in a canned food product indicates an inadequate preserving process. With increasing tourism to areas where food-borne botulism is reported regularly special requests for botulism antitoxin may become necessary. Preparing an inventory of available reserve stock in Europe would appear to be a necessary and valuable undertaking.

\section{Introduction}

Botulism is a disease caused by the neurotoxin of Clostridium botulinum. Seven serotypes of botulinum neurotoxin have been identified, A to G. Serotypes A, $B, E$ and rarely $F$, can affect humans. Types $A$ and $B$ are related to food-borne botulism, of which type $B$ seems to predominate in Europe [1]. Type $E$ is associated with consumption of seafood products [2]. Serotypes C and D cause botulism in animals (birds, mammals), but not in humans. With increased standards of food processing and preservation, food-borne botulism has become a rare disease in the Netherlands. According to the Dutch law on public health, botulism is a notifiable disease, and each year on average one case is reported [3]. These cases presumably result either from contaminated honey (infant botulism), injection of contaminated heroin, or consumption of unprocessed food which has been purchased abroad and consumed abroad or in the Netherlands after returning.

\section{Outbreak description}

On 24 June 2008, the Centre for Infectious Disease Control (Clb) of the Dutch National Institute for Public Health and the Environment (RIVM) was contacted by a medical repatriation organisation about four Dutch patients with clinical signs of botulism, hospitalised in Fethiye, Turkey. The first case had been admitted on 21 June with signs of botulism and treated with botulism antitoxin. Two days later, three more Dutch patients from the same tourist group were admitted and considered epidemiologically related cases. Since all locally available antitoxin had been used for treatment of the first patient, urgent repatriation was requested for the other three patients for treatment in the Netherlands.

The patients belonged to a group of nine participants of a mini cruise, including seven tourists, a cook and the ship owner. All nine were Dutch and had started a sailing trip on 17 June for the duration of one week.

In the Netherlands, an outbreak investigation was initiated into the nine participants of the cruise. The onset of symptoms was between the afternoon of 18 June and 24 June (Figure 1).

In this cluster, a confirmed case was defined as a person who participated in the sailing trip from 17 June onwards, who met the clinical criteria for botulism (at least signs of bilateral cranial nerve neuropathy as

\section{FIGURE}

Cases of botulism by day of onset of disease among cruise participants, Turkey, 17-24 June $2008(\mathrm{n}=8)$

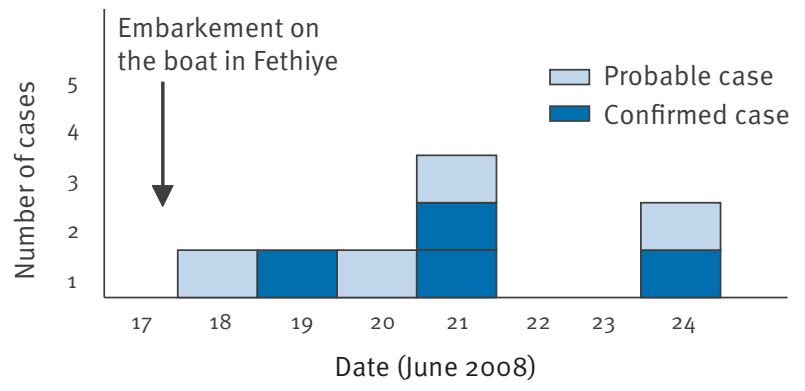


diplopia, blurred vision, dysphagia, bulbar paralysis and/or peripheral symmetrical muscle weakness), with laboratory confirmation (toxin in serum or faeces, or C. botulinum cultured in faeces). A probable case was defined as a person who participated in the sailing trip starting on 17 June and who met the clinical criteria for botulism.

The RIVM informed the Turkish National Focal Point (NFP) about the situation because the Dutch patients might have been part of a larger cluster. The Turkish NFP reported to the RIVM that no additional cases of botulism were reported in Fethiye.

\section{Clinical characteristics and treatment}

The first patient was admitted to hospital with symptoms of blurred vision, diplopia, dry mouth, dysphasia, dysarthria and muscle weakness. The diagnosis botulism was supported by electromyogram and botulism antitoxin was administrated. The three following patients, including the cook, returned to the Netherlands for treatment on 25 June and were admitted to different hospitals [4]. As their clinical symptoms matched with botulism, botulism antitoxin type A, B, $E$ was administered to all of them. Three other group members were repatriated one day later and were also hospitalised with signs of botulism.

Eight of the nine group members developed clinical symptoms of botulism. Seven of the eight patients were admitted to hospital, in Turkey and/or the Netherlands. The symptoms reported most by the seven patients were dysphagia $(n=7)$, dry mouth $(n=7)$, dysarthria $(n=6)$, feeling of 'thick tongue' $(n=6)$ and tiredness $(n=5)$. Also change in voice $(n=4)$, subjective weakness of muscle $(n=4)$, hoarseness $(n=3)$, dizziness $(n=4)$, diplopia $(n=3)$ and blurred vision $(n=3)$ were reported.

Five patients developed symptoms to such an extent that botulism antitoxin was administered in Turkey (one person) or the Netherlands (four persons). In the Netherlands antitoxin administration was based on the patients' clinical signs in combination with the epidemiological connection; laboratory confirmation was not waited for. As botulism is a rare disease in the Netherlands, the available stock of antitoxin is limited.

TABLE 1

Food items consumed by cruise participants in Turkey on 17 and 18 June 2008

\begin{tabular}{|c|c|c|c|c|c|c|c|c|c|}
\hline Case number & 1 & 2 & 3 & 4 & 5 & 6 & 7 & 8 & 9 \\
\hline \multirow[t]{2}{*}{ Date of onset of disease } & 18.6 & 19.6 & 20.6 & 21.6 & 21.6 & 21.6 & 24.6 & 24.6 & - \\
\hline & $\begin{array}{l}\text { Probable } \\
\text { case }\end{array}$ & $\begin{array}{l}\text { Con- } \\
\text { firmed } \\
\text { case }\end{array}$ & $\begin{array}{l}\text { Probable } \\
\text { case }\end{array}$ & $\begin{array}{l}\text { Con- } \\
\text { firmed } \\
\text { case }\end{array}$ & $\begin{array}{l}\text { Con- } \\
\text { firmed } \\
\text { case }\end{array}$ & $\begin{array}{c}\text { Probable } \\
\text { case }\end{array}$ & $\begin{array}{c}\text { Probable } \\
\text { case }\end{array}$ & $\begin{array}{l}\text { Con- } \\
\text { firmed } \\
\text { case }\end{array}$ & $\begin{array}{l}\text { Non- } \\
\text { case }\end{array}$ \\
\hline \multicolumn{10}{|l|}{17 June 2008} \\
\hline $\begin{array}{l}\text { Lunch: } \\
\text { Pasta salad: spicy sausage, pesto, capers, } \\
\text { pickles, garlic at water, black olives }\end{array}$ & Yes & Yes & Yes & Yes & Yes & $\begin{array}{l}\text { Yes (no } \\
\text { pickles) }\end{array}$ & Yes & Yes & $\begin{array}{l}\text { Yes } \\
\text { (no } \\
\text { ol- } \\
\text { ives }\end{array}$ \\
\hline \multicolumn{10}{|l|}{ Dinner in restaurant on the mainland: } \\
\hline $\begin{array}{l}\text { Starters: } \\
\text { Meze: Eggplant, cheese rolls, tzatziki, salad } \\
\text { (tomatoes, green beans, cucumber, feta cheese } \\
\text { and yoghurt) and rice salad }\end{array}$ & $\begin{array}{l}\text { Yes (no } \\
\text { tzatziki) }\end{array}$ & $\begin{array}{l}\text { Yes (no } \\
\text { egg- } \\
\text { plant, no } \\
\text { salad) }\end{array}$ & $\begin{array}{l}\text { Only one } \\
\text { cheese } \\
\text { roll }\end{array}$ & $\begin{array}{l}\text { Yes (no } \\
\text { tzatziki) }\end{array}$ & $\begin{array}{l}\text { Yes (no } \\
\text { tzatziki) }\end{array}$ & Yes & $\begin{array}{l}\text { Yes (no } \\
\text { tzatziki) }\end{array}$ & Yes & $\begin{array}{l}\text { Only } \\
\text { salad }\end{array}$ \\
\hline \multicolumn{10}{|l|}{ Main course: } \\
\hline Chicken & NA & No & NA & NA & Yes & No & NA & No & No \\
\hline Grilled fish with onion and tomatoes & Yes & Yes & Yes (a bit) & Yes & NA & NA & Yes & Yes & No \\
\hline Fried calamari & NA & No & NA & NA & NA & Yes & NA & No & Yes \\
\hline Meat & NA & No & NA & NA & NA & No & NA & No & No \\
\hline \multicolumn{10}{|l|}{18 June 2008} \\
\hline $\begin{array}{l}\text { Breakfast: } \\
\text { Bread with Dutch cheese (from the Netherlands) }\end{array}$ & NA & Yes & NA & NA & NA & Yes & NA & Yes & NA \\
\hline $\begin{array}{l}\text { Lunch: } \\
\text { Chicken soup (with canned coconut milk and } \\
\text { canned corn) }\end{array}$ & Yes & Yes & Yes & Yes & Yes & Yes & Yes & Yes & Yes \\
\hline $\begin{array}{l}\text { Dinner: } \\
\text { Meat roll (with canned green peas, canned } \\
\text { tomato puree and canned minced meat) }\end{array}$ & Yes & No & Yes & Yes & Yes & Yes & Yes & Yes & Yes \\
\hline
\end{tabular}

NA: not able to remember. 
With this sudden request, additional antitoxin had to be delivered by courier from the emergency stock of the manufacturer in Marburg, Germany. All patients recovered.

\section{Food questionnaire}

All group members were asked to complete a questionnaire on food items consumed since the onset of the trip. As the average incubation time for food-borne botulism is 12 to 72 hours (range: two hours to eight days) and the first patient had developed aspecific symptoms of gastroenteritis during the afternoon of 18 June, food poisoning at the beginning of the sailing trip in Turkey was considered most likely. Therefore, the food questionnaires focused on food consumed on 17 June (lunch prepared on the ship and food served in a restaurant) and 18 June (all meals prepared on the ship). By 4 July, all seven tourists and the cook had returned to the Netherlands and the patients were interviewed by their local municipal health services. The ship owner, who stayed in Turkey, sent his questionnaire by mail.

Since the canned food items came from a small stock on board that had also been used in previous sailing trips, the 15 participating tourists of these previous trips were contacted by email to inquire whether they had developed symptoms. They did not report any symptoms and therefore were not included in the study.

The food items served and consumed by the nine group members are listed in Table 1.

Since the group was small, no statistical analysis could be done. In the food histories, special attention was given to differences in food items eaten by the patients compared to the only group member without symptoms, number 9. On board, this person did not eat the locally purchased black olives in the salad served during lunch on the first day. Among the food items prepared on board, the black olives were therefore suspected to be the most likely source of the outbreak. The preserving conditions for these olives before packing had not been controlled, and therefore may have been more prone to contamination. Unfortunately, no leftovers of these olives were available for investigation.

Regarding food eaten on the mainland, the person without symptoms only ate salad and fried calamari in the restaurant during the dinner of 17 June. The patient with the fewest symptoms, case number 3 , also ate little at that restaurant: only one cheese roll and a bit of fish. From food items served at the restaurant, the meze (a Turkish starter) and the fish were most suspected because these specific items were eaten by the confirmed cases. The Turkish NFP was informed on these results.

\section{Microbiological investigation}

Serum and faecal samples of all seven hospitalised patients were collected in the Netherlands for laboratory confirmation of botulism. The ship owner, who stayed in Turkey, and the group member without symptoms did not participate in the laboratory investigation. At the Central Veterinary Institute of Wageningen UR (CVI), detection of botulism toxins in serum and faeces was performed by the mouse bio-assay according to the protocol of the United States Centers for Disease Control and Prevention [5] with some minor changes. Faeces were cultured for isolation and detection of $C$. botulinum. Typing of botulism toxins was done by the mouse neutralisation bio-assay with toxin-specific antibodies.

In four patients, the diagnosis of botulism was confirmed by faecal culture of $C$. botulinum type B. In none of their sera or faeces, botulism toxin could be detected. This resulted in four confirmed cases, four probable cases (three patients who tested negative and the ship owner who was not tested) and one 'noncase' (the person without symptoms).

\section{Analysis of food items}

The cook had bought all canned food items at several local supermarkets. After each sailing trip she discarded all open cans and thoroughly cleaned the kitchen of the ship. Because the ship owner preferred investigation in the Netherlands, he sent unopened locally purchased food items, from the stock on board that was used for the meals, to the CVI in the Netherlands

TABLE 2

Laboratory investigation of food items consumed by cruise participants in Turkey on 17 and 18 June 2008

\begin{tabular}{|l|c|c|c|c|c|}
\hline Food & Packaging & $\mathbf{p H}$ & Detection of botulinum toxin & Detection of C. botulinum & No \\
\hline Black olives & Home-packed & 5,00 & No & No \\
\hline Pickles & Can & 3,97 & No & No \\
\hline Pesto & Jar & 4,23 & No & No \\
\hline Garlic & Jar & 4,14 & No & Yes \\
\hline Green peas & Can & 4,73 & No & No \\
\hline Pineapple & Can & 3,89 & No & C. botulinum type D \\
\hline Coconut milk & Can & 5,50 & No & No \\
\hline Corn & Can & 5,60 & 5,56 & No & No \\
\hline Corn & Can & & No & \\
\hline
\end{tabular}


for further investigation. Food specimens were tested for $C$. botulinum toxin and organisms according to the above protocol, and the $\mathrm{pH}$ was measured.

The results of the laboratory investigation of the food samples done in the Netherlands are summarised in Table 2. The pH of five of nine items was above 4.6, which is considered as the minimum $\mathrm{pH}$ at which C. botulinum can grow. Together with other factors such as temperature, water activity and redox potential, $\mathrm{pH}$ plays a role in preventing the growth and toxin production of $C$. botulinum during the conservation process and storage [5]. C. botulinum type D was isolated from a can of green peas. Although this toxin type differs from the one diagnosed in the patients, its presence in canned food shows at least an inadequate conservation process. This result was communicated to the Turkish authorities.

\section{Conclusion}

This is the first notified outbreak of botulism among Dutch nationals. Eight tourists were affected during a sailing trip in Turkey by $C$. botulinum type $B$. In the literature, clusters of food-borne botulism are often described as resulting from home-preserved products (mainly tofu, green olives and fish [6-8]) or canned products (fish, asparagus, roasted mushrooms [1]). In Turkey, clusters of botulism have resulted from canned roasted mushrooms [9] and çakşir (Ferula orientalis, a regionally grown vegetable) [10]. More recently, a cluster of 10 patients with botulinum poisoning from eating süzme yoghurt has been described [11]. The authors of that article also noted that botulism in Turkey is mostly associated with the consumption of home-prepared foods, especially vegetables such as green beans, tomato or red pepper preserves.

For this cluster, the restaurant visited on 17 June was initially considered as the most likely source, because the one group member that had no symptoms had only eaten salad at this restaurant and because homemade products may have been served. The most likely sources indicated by the food questionnaires were the meze (in particular the cheese rolls) and fish served at the restaurant. However, because fish is more usually associated with $C$. botulinum type $E$, whereas C. botulinum type B was isolated from four of the patients described here, the fish is not likely to have been the source of the outbreak. Although a contamination in the meze cannot be ruled out, no other cases associated with this restaurant, nor feedback from the local investigation of the restaurant were reported by the Turkish national authorities. Therefore the location is now considered less likely as the source of the outbreak.

The meals on board were prepared from locally purchased food such as commercial canned items, bread and home-packed black olives, as well as Dutch cheese that the cruise members had brought from the Netherlands. The laboratory investigation in the
Netherlands of food items purchased in Turkey revealed C. botulinum type $D$ in a can of green peas, which had the same trademark as the peas used for the dinner of 18 June. However, C. botulinum type D is not associated with human illness. In addition, canned peas were ruled out by the food questionnaires because the first patient had already reported gastrointestinal symptoms earlier that day before the dinner with the canned peas was served. While these symptoms may have been coincidental and had another cause, the person without symptoms did report eating the green peas which made this food item also a less likely source.

The $\mathrm{pH}$ of the home-packed olives, the coconut milk and the corn was not low enough to prevent growth of $C$. botulinum. Since growth of $C$. botulinum is influenced by many other factors as well, it is difficult to draw conclusions from this finding. However, according to the food questionnaire, the black olives remain the most likely source for the cluster, although this cannot be confirmed as no leftovers were available for investigation.

\section{Discussion}

The lack of locally available antitoxin for treatment of the patients in Turkey was a major issue in this outbreak and the reason for the repatriation of the Dutch patients. Essential in botulism treatment is timely administration of antitoxin, preferably within 24 hours [4] after onset of the disease, as the antitoxin prevents free toxin from binding to the presynaptic membrane resulting in paralysis.

Botulism is a rare disease, and antitoxin is expensive and has a short shelf-life. Also the stock of antitoxin in the Netherlands is therefore small. In this particular incident, it was possible to purchase emergency supplies of antitoxin from the German manufacturer. In preparation for future potential food-borne outbreak of botulism it would be useful to share information among European countries on national stocks of antitoxin that could be available for exchange in outbreak situations involving several patients. This approach could also be valuable for other antitoxins such as diphtheria antitoxin as well. The European Centre for Disease Prevention and Control has been approached with the request for such an inventory.

\section{Acknowledgements}

The authors would like to thank the following Municipal Health Services: GGD Hollands Midden (Tiffany Smith), GGD Gelderland Midden (Toos Waegemaekers), GGD Regio IJsselVecht (Gerda Kaspers) and GGD Hollands Noorden (Harm Menger) for collecting the questionnaires, and Mark de Boer (LUMC) for cooperation in the repatriation of the first patients. Barbara Schimmer (RIVM) contributed to the data analyses. 


\section{References}

1. Therre H. Botulism in the European Union. Euro Surveill. 1999;4(1):2-7. pii=48. Available from: http://www. eurosurveillance.org/ViewArticle.aspx?Articleld $=48$

2. McLauchlin J, Grant KA, Little CL. Food-borne botulism in the United Kingdom. J Public Health (Oxf). 2006;28(4):337-42.

3. Rahamat-Langendoen JC, van Vliet JA, van Lier EA.

Rijksinstituut voor Volksgezondhed en Milieu (RIVM) [Staat van Infectieziekten in Nederland 2007]. Rapport 210211004/2008. Bilthoven;2008. [Dutch]. Available from: http://www.rivm.nl/ bibliotheek/rapporten/210211004.pdf

4. de Boer MG, van Thiel SW, Lambert J, Richter C, Ridwan $\mathrm{BU}$, van Rijn MA, et al. [Disease outbreak of botulism food poisoning on a mini cruise]. Ned Tijdschr Geneeskd. 2009;153(16):760-4.

5. Centers for Disease Control and Prevention (CDC). Botulism in the United States 1899-1996. Handbook for Epidemiologists, Clinicians, and Laboratory Workers. Atlanta, Georgia. CDC; 1998. Available from: http://www.cdc.gov/ncidod/dbmd/ diseaseinfo/files/botulism.PDF

6. Foodborne botulism from home-prepared fermented tofu--California, 2006. MMWR Morb Mortal Wkly Rep. 2007;56(5):96-7.

7. Cawthorne A, Celentano LP, D’Ancona F, Bella A, Massari M, Anniballi $F$, et al. Botulism and preserved green olives. Emerg Infect Dis. 2005;11(5):781-2.

8. Sobel J, Tucker N, Sulka A, McLaughlin J, Maslanka S. Foodborne botulism in the United States, 1990-2000. Emerg Infect Dis. 2004;10(9):1606-11.

9. Cengiz M, Yilmaz M, Dosemeci L, Ramazanoglu A. A botulism outbreak from roasted canned mushrooms. Hum Exp Toxicol. 2006;25(5):273-8.

10. Erol S, Kursat H, Parlak M, Cetin K, Alici HA, Gorgun S. An outbreak of food-borne botulism. Eur J Anaesthesiol. 1999;16(7):500-1.

11. Akdeniz H, Buzgan T, Tekin M, Karsen H, Karahocagil MK. An outbreak of botulism in a family in Eastern Anatolia associated with eating suzme yoghurt buried under soil. Scand I Infect Dis. 2007;39(2):108-14 